\title{
Translating Knowledge about Parental Mental Illness to the Field of Practice
}

Camilla Lauritzen ${ }^{*}$ and Charlotte Reedtz

Center for Child and Youth Mental Health \& Child Welfare, UiT- Arctic University of Norway, Norway

*Corresponding author: Camilla Lauritzen, UiT- Arctic University of Norway, Norway, Tel: 47 77645871; E-mail: Camilla.Lauritzen@uit.no

Received date: August 6, 2014; Accepted date: September 23, 2014; Published date: October 2, 2014

Copyright: ( 2014 Lauritzen C, et al. This is an open-access article distributed under the terms of the Creative Commons Attribution License, which permits unrestricted use, distribution, and reproduction in any medium, provided the original author and source are credited.

\begin{abstract}
Parental mental illness is a powerful risk factor, with a potential of serious impact for the children. Mental health problems are often transmitted from one generation to the next. Parental mental illness is however considered to be a malleable risk-factor, which means there are measures that can be taken to counteract the risk. Nevertheless, transferring this knowledge to the field of parental mental illness has been very difficult. The aim of the current study was to explore the relationship between knowledge and attitudes towards a child perspective in adult mental health services and actual clinical practice. The aim was furthermore to investigate which factors are hindering or promoting the translation of new knowledge to the field of practice. In the present study results will be interpreted in light of the theory of reasoned action.
\end{abstract}

Keywords: Implementation; Practitioner behavior change; Knowledge transfer; Parental mental illness

\section{Introduction}

Several international studies the past two decades have indicated that children with mentally ill parents are at risk of developing mental health problems themselves $[1,2]$. Parental mental illness is considered a powerful risk-factor, with a potential of serious impact for the children. E.g., parents with depression have more difficulties in interaction with their children, are more intrusive, less involved and less responsive [3-5].

Parental mental illness is however considered to be a malleable riskfactor, which means there are measures that can be taken to counteract the risk. Internationally there is now an expanding evidence base to demonstrate the effectiveness of a number of interventions to prevent children of mentally ill parents from developing problems themselves [6-9]. However, implementing such interventions requires a systematic approach to change practitioner behavior within adult mental health services.

Proctor and colleagues (2008) found that one of the most critical issues in mental health services research is the gap between what is known about effective treatment and what is provided to consumers in routine care [10]. We know much about interventions that are effective, but make little use of them to help achieve important health outcomes for children, adults and families [11].

A national study conducted in Norway in 2005 showed that the services available to children of mentally ill parents were insufficient [12]. In spite of the fact that the risk factors for these children are known, establishing a change of practice to increase identification and support for these children has been challenging. Some studies have found that worker attitudes may be problematic when attempting to integrate a child focus in mental health care for adults. Korhonen and colleagues (2008) [13] documented that mental health nurses do not regard the children of patients as their responsibility. Some workers may also believe that family members may cause or increase the mental illness by laying extra burdens on the patient [14] and therefore hesitate to include a family perspective in their treatment of patients.

In order to improve the situation for these families, several changes in health legislation [15] were made. The new legislation became effective in 2010. The intention behind the legislation amendments was to increase early identification and to encourage processes that enable children and parents to master the situation better when a parent is mentally ill. The changed Health Personnel Act ( $\$ 10$ a) made it mandatory for health professionals to 1) identify if patients have children and 2) to provide information and necessary follow-up for children under 18 years who have parents that receive health care for mental illnesses, substance abuse disorders or serious somatic illness or injury.

Many strongly believe that increasing knowledge and changing attitudes also change people's behavior. This is linked to a belief that awareness campaigns, education and a general focus on a subject, will cause behavior change in people. Within health promotion campaigns, this has been a particularly common strategy [16], for instance campaigns to encourage people to stop smoking, anti-bullying programs, nutrition campaigns to prevent obesity and lifestyle campaigns to promote exercise and practice in everyday life. In the study of changing clinical practice to safeguard children of mentally ill parents, this view implies that information and courses for health professionals should have the potential to change clinical practice.

There is reason to assume that people's behaviors are determined by their beliefs attitudes and intentions $[17,18]$. This approach is called the reasoned actions approach and implies that people's behavioral intentions are likely to be connected to their beliefs about performing a behavior. This means that the beliefs a person has serves as a cognitive foundation from which attitudes, perceived social norms, perceptions of controls and intentions stems from [17]. From this foundation, intentions and attitudes are assumed to follow in a reasonable manner, and cause a reasoned behavior.

There are three main predictors of intentions and behavior in this model; Behavioral beliefs, Normative Beliefs, and control beliefs. These three predictors are generally influenced by a number of background 
factors. According to Ajzen \& Fishbein, there are a multitude of variables that could potentially influence the beliefs of people; age, gender, ethnicity, socioeconomic status, education, nationality, personality, values, intelligence etc. In our previous studies we have found that age, gender and educational background significantly were linked to the question of whether or not children of mentally ill parents should be given attention within mental health services for adults $[19,20]$. However, based on Ajzen and Fishbeins theory of attitudes and intentions in relation to behavior change, there is no reason to believe that awareness campaigns and education alone will create a potential to change health professionals' behavior and actions in everyday practice [17].

Results of a study conducted one year after the legislation had been altered showed that a large part of the health personnel have the knowledge about the risk factors for children of mentally ill parents, they have positive attitudes toward including this perspective in their clinical practice, and they also have the intention to start identifying and supporting children of mentally ill parents $[19,20]$. However, in a study of register data conducted at the same hospital, the results showed that contrary to the facilitating attitudes and good intentions, the new routines in which children of mentally ill patients are identified and followed up have not been systematically implemented in adult mental health services [21]. The results of this study indicated that the strategy of changing legislation, policies and procedures to achieve the goal of identification and protection of children at risk represent a paper implementation approach to behavior change, and is insufficient [11]. This implies that is not sufficient to simply point out why something should change, how the changes are to come about must also be determined. There is no reason to expect that positive general attitudes to safeguarding children, as well as increased knowledge about the risk of these children will automatically change clinical practice. There is no theoretical or empirical foundation to expect specific skills and behaviors to arise from a general dissemination of knowledge and attitudes.

Based on the realization that strengthening health professionals' intentions, attitudes and knowledge had not been a successful approach to change practitioner behavior, the aim of the current study was to explore the relationship between positive attitudes and actual clinical practice. The aim was furthermore to investigate which factors are hindering or promoting the implementation of new routines, three years after altered health legislation made it mandatory to identify and provide support for children of mentally ill patients. In the present study results will be interpreted in light of the theory of reasoned action.

In light of Ajzen and Fishbeins model identification and providing follow up for children represents the behavior we investigated.

\section{Methods}

This qualitative study is a part of a longitudinal study that evaluates the process of implementing interventions for children of patients in the adult mental health care of a University Hospital in Northern Norway [22]. The participants in this study are mental health care workers who also had been assigned the role as child responsible staff in their wards. Data were gathered through focus group interviews, based on a semi-structured interview guide. All interviews were conducted in 2013.

\section{The interviews and the interview guide}

The use of focus groups emphasizes communication between research participants in order to generate data. We conducted three focus group interviews. Additionally, we interviewed one informant alone, due to challenges related to finding a date that was suitable for all parties. By using focus groups, we were able to catch the variability of different opinions and perspectives among the informants [23].

The initial questions focused on current clinical practice in terms of mental health patients who are also parents. We discussed attitudes to including a focus on children in the mental health services for adults. Furthermore, we investigated whether or not health personnel had the intentions to start identifying and providing support for the children of their patients. Finally, we discussed which factors the personnel perceived as hindering or facilitating the changes of practice to include a child focus.

\section{Recruitment and subjects}

The recruitment for participation was done by a written invitation sent out by e-mail to child responsible staff in the three northernmost counties in Norway. In the participating clinic (and throughout Norway), the workforce is organized in interdisciplinary treatment teams, where all members of the team, regardless of educational background, are responsible for treatment of the patient. The teams typically consists of general nurses, psychiatric nurses, psychologists, psychiatrists and special teachers. However, the child responsible staff we interviewed mainly consisted of nurses or social workers and all of them were women. The sample included 8 subjects, and each focus group consisted of two-three staff members, in addition to the project leader and the research fellow.

\section{Procedure}

The interviews were conducted within the hospital, and both authors participated in the focus groups. The informants received written information about the project in advance, and gave informed consent to participate. The informants already knew about the preexisting strategies within the hospital to change clinical behavior in order to achieve a more child focused practice. Both authors participated in the interview process. The interviews each lasted between 60-90 minutes and were audio-taped and transcribed.

\section{Data analysis}

The audio-taped interviews were transcribed verbatim by one of the authors. Then the other author read through the transcription to make sure that everything was included in the transcription.

The data was analysed using a Framework Analysis (FA) approach, a strategy that is often referred to as "thematic analysis". FA provides systematic and visible stages to the analysis process, so that others can be clear about the stages by which the results have been obtained from the data [24]. Even though the general approach in FA is inductive, this form of analysis allows for pre-determined issues to be investigated [25].

FA has 5 key stages; familiarisation, identifying a thematic framework, indexing, charting and interpreting. The familiarisation is when the transcription and reading of the data took place. The data material was systematised, and the process of identifying a thematic framework was initiated. This means that the initial coding took place, developed both from emerging issues and from pre-existing questions 
Page 3 of 5

based on existing research and theory. The thematic framework in this study is the theory of reasoned action, based on Ajzen and Fishbein $(2005,2010)$. The process of applying the theory to the data (indexing) was then initiated. The data was consecutively coded into themes. The next part of the analysis process was charting. In the charting process the data was thematically organized in matrixes, forming the basis of tables to interpret. The final stage of analysis was the interpretation stage. The data was systematically explored to reveal relevant explanations and associations linked to the research question.

\section{Results}

The results of this study are in line with previous research we have conducted, showing that health personnel have positive attitudes to including a focus on children in the treatment of patients and that the clinic has good intentions in terms of changing the practice to include this $[19,26,27]$. However, only a total of 219 individuals responded, representing a response rate of $50 \%$. This may have biased the results as we expect the participants to have more knowledge, more positive attitudes and beliefs regarding the inclusion of a family perspective in the treatment of patients. All the child responsible staff we interviewed reported they agree that identifying and supporting children of mentally ill patients is an important task that should be incorporated in clinical practice. They also reported they intended to incorporate identification and follow up in their routines.

The results furthermore confirmed the idea that the health personnel are aware of the risk factors children of mentally ill parents are subject to, and thereby they are aware of the negative consequences related to not identifying and following up the children. In terms of the approval or disapproval of the behavior by respected individuals, the results were somewhat divided. Even though they all were aware of the legislative authorities approval of changing clinical behavior, the child responsible staff had varying experiences connected to approval. Some of the health personnel reported the new routines to be approved by their peers and their managers, some had experienced indifference, and some had the sense that the new routines were disapproved.

We were also able to detect several factors that were considered as facilitating or hindering factors in order to translate the positive attitudes and the good intentions to behavior change in terms of changing clinical practice. Detailed results are displayed (Table 1).

\section{Hinders related to behavioral beliefs}

Psychiatrists are reluctant

Limited knowledge about other agencies to collaborate with, e.g., child protection services

Cultural differences and minority families

Inter-agency and inter-professional collaboration is poor

Hinders related to normative beliefs

Too many items in the identification forms

Financial cutbacks

Not enough time to plan conversations with families

Reluctant families who worry about custody issues

Several other projects competing about limited resources

\begin{tabular}{|l|}
\hline Procedures for all personnel have not been streamlined \\
\hline Colleague supervision is limited \\
\hline Skills-training is at a low level \\
\hline $\begin{array}{l}\text { Distribution of responsibility has not been even (to avoid the vulnerability of } \\
\text { having only one responsible staff-member) }\end{array}$ \\
\hline Hinders related to control beliefs \\
\hline Complicated documentation forms and systems \\
\hline Difficult to change well established habits \\
\hline High turn \\
\hline Unsystematic allocation of human resources \\
\hline Complicated family structures \\
\hline
\end{tabular}

Table 1: Factors hindering the intention to change behavior.

\section{Behavioral beliefs}

According to the reasoned actions approach the term behavioral beliefs refers to a person's fundamental beliefs about the positive or the negative consequences of a certain behavior, and these behavioral beliefs are assumed to determine people's attitude toward performing the behavior. In this study the behavioral beliefs were found to be as follows: The health care workers we interviewed believed that identifying and supporting the children is a task they should take on in adult mental health services. They were positive about the new routines to be implemented, and they had high expectations towards the interventions having a positive outcome for children. They also believed that intervening early may prevent the intergenerational transfer of psychopathology. These behavioral beliefs were expressed as positive attitudes towards incorporating a child perspective in the treatment of mentally ill patients.

However, according to the participants psychiatrist seemed more reluctant to incorporate the new practice in their clinical work. Furthermore, limited knowledge about other agencies to collaborate with and poor inter-agency and inter-professional collaboration feeds into more negative attitudes toward behavior change in clinical practice. Also, the complexity of working with minority families and cultural differences is challenging for health personell.

\section{Normative beliefs}

The term normative beliefs refer to the belief that important individuals or groups would approve or disapprove of health personals particular behavior. These normative beliefs produce a perceived social pressure to engage or not engage in the behavior. In this context, the social pressure to identify and support children of mentally ill parents is present on many levels. The health legislation has been altered to encompass this belief, and the health authorities have laid a clear premise that the behavior (identifying and supporting children) is formally approved of. Furthermore, some of the managers and the child responsible staff generally expressed that they approve of the particular behavior. However, the informal leaders have not been taken into account, and based on the interviews there is reason to believe that some health care workers strongly disapprove of the notion that identification and supporting children is a task they should take on. Additionally, the informants reported that some of the ward- 
managers had expressed reluctance to allocate enough time and resources to the new tasks. The perceived social pressure to engage or not engage in also related to financial cutbacks, time available to plan conversations with families, and time to document clinical practice in new identification forms. Furthermore, lack of streamlines procedures, distribution of responsibilities, skills-training and colleague supervision impedes the normative beliefs for health personnel.

\section{Control Beliefs}

The third aspect of understanding behavior is linked to control beliefs. This term refers to personal and environmental factors that can help or impede the attempts to carry out the behavior [18] These control beliefs are linked to Bandura's [28] theory of high or low selfefficacy (1998), or perceived behavioral control with regard to the behavior [18]. Fishbein and Ajzen state that if there are many facilitating factors present, perceived behavior control should be high. In the present study, we did however find many hindering factors, such as complicated documentation forms and systems, high turnover rates among personnel in the clinic, and unsystematic allocation of human resources. Our participants emphasized that it is difficult to change well established documentation habits and that complicated family structures added to an already clinical challenge. Furthermore, there are no standardized control-mechanisms within the hospital to monitor whether or not the health personnel has successfully managed to take on the new tasks. This means that the hospital managers or health authorities do not exercise control in terms of monitoring the new tasks. This implies that there may be reason to believe that the perceived behavioral control in this study is low (Figure 1).

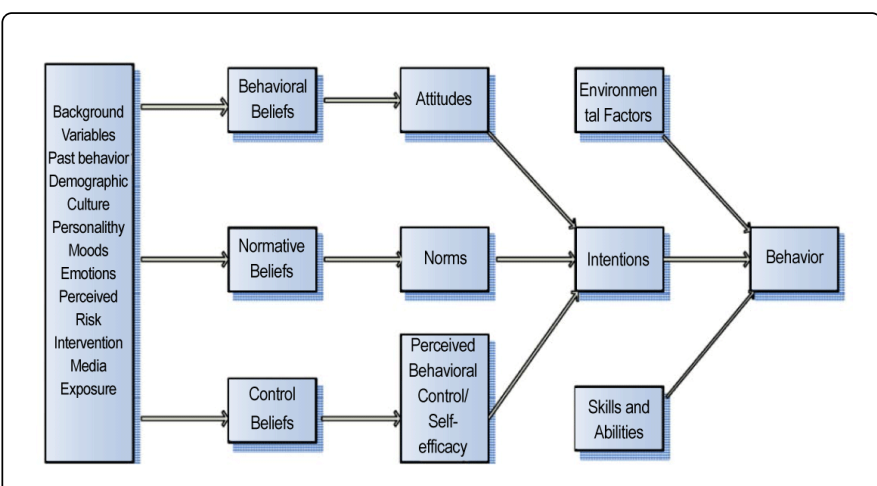

Figure 1: The reasoned action model by Ajzen \& Fishbein, 2010 [18].

\section{Discussion}

To achieve a practitioner behavior that incorporates a focus on patient's children, it is necessary to create the intention to behave in this manner. There are three main predictors of intentions; attitudes, norms and control, and the practitioner beliefs related to these three predictors are directly linked to the actual behavior.

In terms of positive attitudes and the behavior beliefs that are the basis of attitudes, we discovered several key aspects in the present study. Even though the participants of this study reported to have positive attitudes toward changing practice, they simultaneously reported several fundamental beliefs about the new practice that may contribute to less positive attitudes toward performing the behavior.
One of the behavioral beliefs they expressed was the reluctance of psychiatrists to incorporate a child focus in the treatment of mentally ill parents. One possible implication of this fundamental belief can be a general negative attitude arising in the clinic to focus time and resources on the patient's children, because the psychiatrists have key roles within the wards and within the treatment teams.

Another important behavioral belief reported by our informants was the limited knowledge about other agencies to collaborate with, e.g., child protection services. It is possible that the lack of knowledge may influence the attitudes towards the importance of changing practitioner behavior in a negative way. Additionally our informants highlighted a poor inter-agency and inter-professional collaboration. It is likely that such premises also may lead to negative attitudes toward the new practice. This may imply that the attitudes predicting the intention to change practice may have been negative, and hence hindering the actual change of practice.

We also discovered several hinders in terms of the normative beliefs, which in turn play a part in the formation of the workforce perceived norms about actually engaging in the behavior. Many of these hinders may be seen as organizational hinders, such as financial cutbacks, time available to plan conversations with families, and time to document clinical practice in new identification forms. It is likely that these organizational barriers create a workforce norm where the notion is not to engage in the new practice. The lack of streamlined procedures, distribution of responsibilities, skills-training and colleague supervision, may be interpreted as a perceived norm within the clinic where a focus on patients' children is not considered a priority. This in turn, is likely to have an impact on the intention to actually carry out the new tasks within the clinic.

The final predictor of intentions to change behavior is linked to control beliefs. Our informants pointed to two important aspects of this dimension. Firstly, there were several personal factors that can impede the attempts to carry out the new clinical practice. The participants reported to have a low sense of control over the new tasks, for example the new documentation forms. They also reported that they thought the new practice was difficult to convey to patients living in complicated family structures. One implication of this may be that the health personnel are reluctant to carry out the behavior because they lack control of the new routines. The second aspect of the control dimension is linked to environmental factors that can impede the attempts to carry out the behavior. The participants of this study pointed to several environmental hinder. Factors reported to be disturbing the rhythm of establishing training, routines and supervision were high turn-over rates and the unsystematic allocation of resources regarding patients' children. This may imply that the premises for integrating the new tasks were random and lacking organizational control. A lack of control-mechanisms within the hospital to monitor whether or not health personnel has successfully managed to take on the new tasks may result in lower intentions to actually carry out the new tasks.

\section{Conclusion}

The results of this study underlines the fact that even though health legislation has been changed in order to safeguard children of mentally ill parents, there is still a need for clear and effective strategies to fully incorporate a child perspective into adult mental health care. The results of this study were interpreted using Ajzen and Fishbein's reasoned action model as a framework. By identifying the core 
components in our data in light of this model, we have come to a more advanced understanding of the implications of the hindering factors related to incorporating new routines in adult mental health services. We now believe that in order to achieve changes in clinical practice, systematic measures to facilitate the predictors of intentions must be taken. By systematically addressing the hindering factors related to behavioral, normative and control beliefs it is possible to facilitate positive attitudes, positive norms and perceived control of the new tasks. This may lead to the emergence of actual intentions to change, and henceforth a changed clinical practice that takes into account the children of mentally ill parents. It seems fair to say that the belief that increasing knowledge and changing attitudes does not alone change people's behavior, and implementation strategies based on this assumption will continue to be impotent.

\section{Ethics}

The study has been assessed by the Regional Committees for Ethics in Medical Research. Additionally, the project has been approved by the data protection officer (DPO) at the participating hospital. The study is in accordance with the Helsinki declaration (World Medical Association, 2008).

\section{Acknowledgements}

We would like to thank the mental health care workers for taking the time to respond to our survey. We also would like to acknowledge Dr. Monica Martinussen and Dr. Karin van Doesum for their contributions in the overall project Children of mentally ill parents at Univeristy of Tromso. The overall project has been financed by the University of Tromso.

\section{References}

1. Beardslee WR, Versage EM, Gladstone TR (1998) Children of affectively ill parents: a review of the past 10 years. J Am Acad Child Adolesc Psychiatry 37: 1134-1141.

2. Gladstone BM, Boydell KM, Seeman MV, McKeever PD (2011) Children's experiences of parental mental illness: a literature review. Early Interv Psychiatry 5: 271-289.

3. Kowalenko NM, Mares SP, Newman LK, Williams AES, Powrie RM, Van Doesum KTM (2012) Family Matters: Infants, Toddlers and Preschoolers of parents affected by mental illness. Early interventions targeting adverse influences on young children and their parents can improve children's outcomes. MJA Open.

4. Murray L, Cooper P (1997) Effects of postnatal depression on infant development. Arch Dis Child 77: 99-101.

5. Van Doesum KTM (2007) An early preventive intervention for depressed mothers and their infants, its efficacy and predictors of maternal sensitivity. RIAGG IJ selland Deventer.

6. Bearslee WR, Wright EJ, Gladstone TR, Forbes P (2007) Long-term effects from a randomized trial of two public health preventive interventions for parental depression. J Fam Psychol 21: 703-713.

7. Fraser C, James EL, Anderson K, Lloyd D, Judd F (2006). Intervention Programs for Children of Parents with a Mental Illness: A Critical Review. The International Journal of Mental Health Promotion 8: 9-20.

8. Reupert A, Maybery D (2011) Programmes for parents with a mental illness. J Psychiatr Ment Health Nurs 18: 257-264.

9. Van Doesum KT, Riksen-Walraven JM, Hosman CM, Hoefnagels C (2008) A randomized controlled trial of a home-visiting intervention aimed at preventing relationship problems in depressed mothers and their infants. Child Dev 79: 547-561.

10. Proctor EK, Landsverk J, Aarons G, Chambers D, Glisson C, et al. (2009) Implementation research in mental health services: an emerging science with conceptual, methodological, and training challenges. Adm Policy Ment Health 36: 24-34.

11. Fixsen D, Scott V, Blase K, Naoom S, Wagar L (2011) When evidence is not enough: the challenge of implementing fall prevention strategies. J Safety Res 42: 419-422.

12. Aamodt G, Aamodt I (2005) Tiltak for barn med psykisk syke foreldre [Interventions for Children of Mentally Ill Parents] Report. RBUP Øst/Sør.

13. Korhonen T, Vehviläinen-Julkunen K, Pietilä AM (2008) Implementing child-focused family nursing into routine adult psychiatry practice: hindering factors evaluated by nurses. Journal of Clinical Nursing 499-508.

14. Maybery D, Reupert A (2009) Parental mental illness: a review of barriers and issues for working with families and children. J Psychiatr Ment Health Nurs 16: 784-791.

15. Norwegian Ministry of Health and Care Services. (2009). Changes in the law.

16. Snyder LB, Hamilton MA, Mitchell EW, Kiwanuka-Tondo J, FlemingMilici F, et al. (2004) A meta-analysis of the effect of mediated health communication campaigns on behavior change in the United States. J Health Commun 9 Suppl 1: 71-96.

17. Ajzen I, Fishbein M (2005) The influence of attitudes on behavior. In Albarracín, D., Johnson, Blair T., Zanna, M.P. (Eds): The handbook of attitudes, Mahwah, NJ, US: Lawrence Erlbaum Associates Publishers 173-221.

18. Fishbein M, Ajzen I (2010) Predicting and changing behavior. The reasoned action approach. Psychology press. Taylor \& Francis Group. New York.

19. Lauritzen C, Reedtz C, Martinussen M, Van Doesum K (2012). Predictors of Workforce Attitudes to Including a Child Perspective in the Treatment of Mentally Ill Parents. Poster presentation, Child and Youth Mental Health Matters, Vancouver, Canada.

20. Lauritzen C, Reedtz C, Van Doesum KT, Martinussen M (2014) Implementing new routines in adult mental health care to identify and support children of mentally ill parents. BMC Health Serv Res 14: 58.

21. Reedtz, Mørch, Lauritzen. (2013) Registreres psykiatriske pasienters barn i elektronisk pasientjournal? -Kritisk søkelys på implementering av ny klinisk praksis i psykisk helsevern for voksne. In press.

22. Reedtz C, Lauritzen C, van Doesum KT (2012) Evaluating workforce developments to support children of mentally ill parents: implementing new interventions in the adult mental healthcare in Northern Norway. BMJ Open 2.

23. Kitzinger J (1995) Qualitative research. Introducing focus groups. See comment in PubMed Commons below BMJ 311: 299-302.

24. Lacey A, Luff D (2001) Qualitative Data Analysis. Trent Focus.

25. Reedtz C, Lauritzen C, van Doesum KT (2012) Evaluating workforce developments to support children of mentally ill parents: implementing new interventions in the adult mental healthcare in Northern Norway. BMJ Open 2.

26. Lauritzen C, Reedtz C, Martinussen M, van Doesum K (2013) Factors that may facilitate or hinder a family focus in the treatment of parents with a mental illness. Journal of child and family studies.

27. Lauritzen C, Reedtz C (2013) Identifying and supporting children of psychiatric patients: Exploring the challenges. Mental Health Practice 16: $12-18$.

28. Bandura A (1998) Health promotion from the perspective of social cognitive theory. Psychology and Health 13: 623-649. 